\section{Lots for DCPs in Edinburgh}

I have just been looking through the most recent issue of Vital and discovered that the DCP course directory (Vital summer 2010 pages 13-16) contained incomplete information about education in Edinburgh.

The University of Edinburgh runs a four year Honours degree in Oral Health Sciences of which I am Programme Director. Within the Dental Institute we also run a Diploma in Dental Therapy module for qualified dental hygienists, the Diploma in Orthodontic Therapy, a dental nurse training programme and various Certificates for Dental Nurses, postqualification. Lots going on here for DCPs!

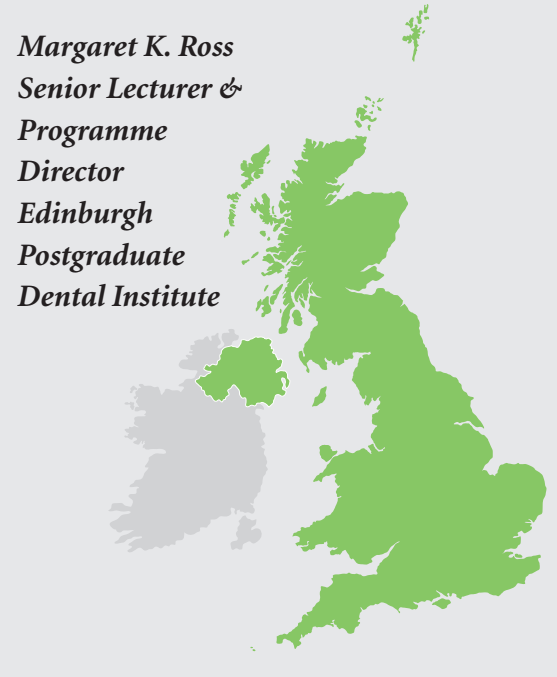

\section{Glasgow nurse training}

Our company has been involved in dental nurse training over the last 25 years and I would be grateful if you would include our details in your next issue: Mentor Training Centre Ltd, 11 Bothwell Street, Glasgow, G2 6LD.

The qualification we offer is NVQ: Level 3 Oral Health Care Dental Nurse.

The website address is www.mentortrainingcentre.co.uk and the telephone number is 01418470722 .

\section{Moira McKenna Centre Manager}

Ed's note: An updated course directory will appear in Vital in summer 2011.

\section{DCP courses in Hull}

Would it be possible to include the following courses for the North East in the next issue of Vital please?

- Foundation Degree in Post Qualifying Dental Nursing Practice

- Dental Radiography for Dental Nurses and Hygienists

- Dental Sedation Nursing for Dental nurses

- Special Care for Dental nurses

- Dental Practice Management

- Supervising and Mentoring Practice

\section{Helen Mawer}

Lecturer/Practitioner

Dept of Health Professional Studies

Faculty of Health and Social Care University of Hull

\section{CPD courses}

\section{for nurses}

I am the DCP (Dental Nurse) Tutor at the Yorkshire \& Humber Postgraduate Deanery, responsible for dental nurse CPD courses in North East Yorkshire and North Lincolnshire.

The Deanery supports dental nurses with accredited NEBDN post qualifications in oral health education, radiography and orthodontic dental nursing.

We provide impression taking competencies, whole team training days and dental nurse specific day and evening lectures.

For course listings please see: www. yorksandhumberdeanery.nhs.uk.

\section{Geraldine Birks LCGI} DCP Tutor (NEYNL)

Yorkshire \& Humber Postgraduate Deanery University of Leeds

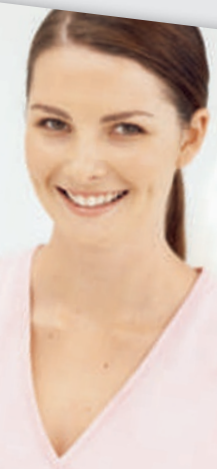

\section{Council reflects the people}

I read with interest the article Why bother with ethics and law? by Mark G. Brennan (Vital spring 2010; 37-39). I felt it dealt comprehensively with the issues facing DCPs in their professional lives, but I would like to correct one inaccuracy in the article.

The Council of the GDC is indeed made up of dentists, DCPs and lay people, but none of them are elected to their positions.

In 2007 the Government published a White Paper entitled: Trust, assurance and safety: the regulation of health professionals in the $21^{\text {st }}$ Century. It set out plans for the future of healthcare regulation in the UK. Guided by this paper it was decided that a smaller, fully appointed Council would be more appropriate.

Our Council is now made up of 24 members (eight dentists, four DCPs and 12 lay people) instead of 29.

For the first time the make up of the Council now evenly reflects the people that provide and receive dental care. The move away from a mostly elected Council, and the involvement of the Appointments Commission in the recruitment process, has opened up the chance to be involved in the Council of the GDC to a whole new range of people from across the UK.

This new Council of the GDC held its first meeting in October last year and is now working towards the challenge of ensuring patient protection is at the forefront of everything we do whilst striving to become a leader in healthcare regulatory excellence.

For more information and profiles on all our Council Members please log on to our website www.gdc-uk.org.

\section{Alison Lockyer \\ Chair, General Dental Council}

Mark G. Brennan responds: I am grateful to Dr Lockyer, Chair of the GDC Council, for helpfully correcting my error. It is of course an important feature of the new GDC that members of the Council are appointed rather than elected, and that the Council now reflects a broader range of representation by dentists, DCPs and lay people through these appointments. This, in my view, helps to promote the setting and maintenance of ethical and other standards for dentistry. I should also like to commend the GDC for the guidance documents - Standards for dental professionals - which are extremely clear and well written. 